\title{
The Adaptability Evaluation of Graduate Employment Information System
}

\author{
Lili Dong \\ The department of Modern management \\ Zhengzhou Technical College \\ Zhengzhou, China \\ E-mail: donglilibaihe@163.com
}

\begin{abstract}
In this paper, a set of evaluation system is proposed by GQM (Goal-Question-Metrics) for graduate employment information system (GEIS). Then based on Similarity to Ideal Solution, the evaluation model is proposed to evaluate GEIS adaptability. Finally, the application of the evaluation system and model is proved via a case, which provides references for optimizing GEIS adaptability.
\end{abstract}

Keywords : Adaptability evaluation; Graduate employment information system; Similarity to Ideal Solution

\section{INTRODUCTION}

Graduate employment information system (GEIS) should have the ability to adapt to the dynamic environment inside and outside to obtain employment information in time and realize information flow in order, i.e., GEIS adaptability. At present, there are few references to GEIS adaptability, and the main researches are as follows: 1) the importance of the information construction of graduate employment [1-5]; 2) countermeasures study on the information construction of graduate employment [6-10]; 3) the management information system of college graduate employment service[11-15]. For example, reference [2] discussed the internet information construction for graduate employment. But most of them are qualitative research and have little relation to GEIS adaptability, let alone the evaluation of GEIS adaptability quantitatively.

Hence, according to GQM (Goal-Question-metrics), this paper proposes a set of adaptability evaluation system, and the corresponding evaluation model is given. The contents can support further research to the optimization of GEIS adaptability.

\section{ADAPTABILITY EVALUATION SYSTEM}

According to GQM, the index set can be obtained, as shown in Fig.1. It includes Cost, Reliability, Robustness, Scalability, and Security.

The indices are shown in detail as follows:

(1) Cost

Two parts of the adjustment costs are considered, including information adjustment cost and module adjustment cost. This index can be classified into four levels:

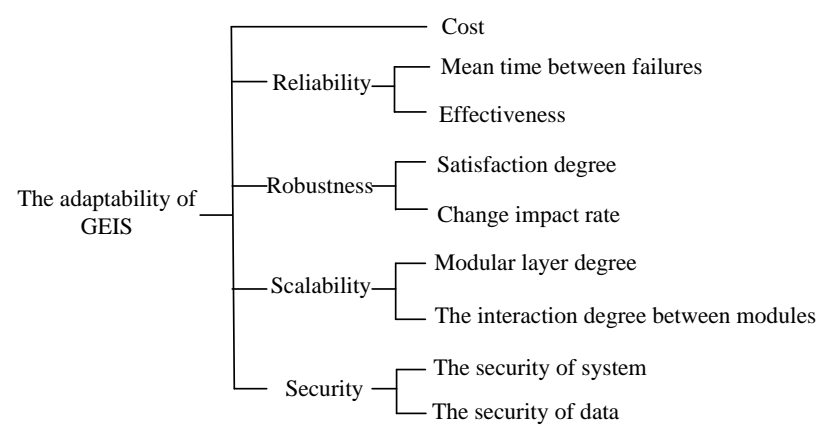

Fig.1 The evaluation index system of GEIS adaptability $\mathrm{A}$ (little money), B(a little money), C(much money), $\mathrm{D}$ (more money).

(2) Reliability

This index set contains two sub-indices including mean time between failures and effectiveness.

(3) Robustness

This index set includes the following sub-indices: satisfactory degree and change impact rate.

1) Satisfactory degree. This index mainly means the satisfaction degree of the customers (including graduates, colleges and society, etc ). This index can be classified into four levels: A(basically satisfaction), B(satisfactory), $\mathrm{C}$ (more satisfactory), $\mathrm{D}$ (most satisfactory).

2) Change impact rate.

This index is a value describing the probability of modules involved in the adjustment among all the modules. This index can be classified into four levels: $\mathrm{A}(0.07 \sim 1)$, $\mathrm{B}(0.05 \sim 0.07), \mathrm{C}(0.03 \sim 0.05), \mathrm{D}(0.01 \sim 0.03)$.

(4) Scalability

This index set mainly contains two sub-indices including modular layer degree and the interaction degree between modules. This index can be classified into four levels: A(bad), B(good), C(better), D(best).

(5) Security

Two kind of security are considered in this index set. One is the security of system and the other is the security of data. This index can be classified into four levels: A(relatively safe), B(safe), C(more safe), D(most safe).

To be mentioned, different indices have different types of values. For the indices like cost, the smaller the better. While for the indices like satisfaction degree and modular degree, 
the bigger the better. And for others, it's better not too big or too small.

\section{THE EVALUATION MODEL}

In this paper, based on the similarity to ideal solution, the modeling process is shown in Fig.2, which is illustrated in detail below via the indices proposed in this paper.

Step 1: According to the proposed index system, the grading standards for evaluation are as follows:

1) As for Cost, the four levels A, B, C and D are 1, 3, 5, and 7 respectively.

2) As for mean time between failures, the four levels A, $\mathrm{B}, \mathrm{C}$ and $\mathrm{D}$ are 7, 5, 3, and 1 respectively.

3) As for effectiveness, the four levels A, B, C and D are $7,5,3$, and 1 respectively.

4) As for satisfaction degree, the four levels A, B, C and $\mathrm{D}$ are 7, 5, 3, and 1 respectively.

5) As for change impact rate, the four levels A, B, C and $\mathrm{D}$ are $1,3,5$, and 7 respectively.

6) As for modular layer degree, the four levels A, B, C and $\mathrm{D}$ are 7, 5, 3, and 1 respectively.

7) As for the interaction degree between modules, the four levels A, B, C and D are 1, 3, 5, and 7 respectively.

8) As for the security of system, the four levels A, B, C and $\mathrm{D}$ are 7, 5, 3, and 1 respectively.

9) As for the security of data, the four levels A, B, C and $\mathrm{D}$ are $7,5,3$, and 1 respectively.

To be mentioned, if the degree is between two standards, the grades are 2,4,6 respectively.

Step 2: Establish the weight of the indices. As there are different weights among different indices, it's necessary to give them different weights according to the Delphi method.

As for the indices proposed in this paper, the weights of them are as follows: $w=\left(w_{1}, w_{2}, w_{3}, w_{4}, w_{5}, w_{6}, w_{7}, w_{8}, w_{9}\right)$

$=(0.05,0.1,0.17,0.25,0.07,0.08,0.06,0.1,0.1) \quad$, where $w_{1}, w_{2}, w_{3}, w_{4}, w_{5}, w_{6}, w_{7}, w_{8}$ represent Cost, Mean time between failures, Effectiveness, Satisfaction degree, Change impact rate, Modular layer degree, The interaction degree between modules, The security of system and the security of data respectively.

Step 3: Establish the sample matrix $S M^{1}$. In this step, according to the grading standards of the evaluation in step 1 , each index is graded by experts, constituting $S M^{\prime}$, then multiplying the weight of each index, and $S M^{2}$ is obtained.

Step 4: Comprehensive evaluation of the sample matrix.

Firstly, obtain the ideal matrix $S M^{0}$. Then calculate the

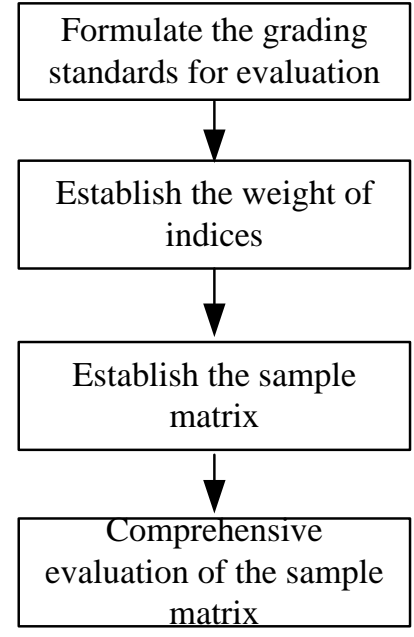

Fig.2 Modeling process of GEIS adaptability

distance $d(1,2, \cdots, n)$ between each GEIS and the corresponding ideal matrix. And in this paper, the Frobenius matrix norm is adopted.

According to the above steps, the final adaptability value is obtained, and the larger the final value is, the better adaptability is.

\section{EXAMPLES}

The evaluation indices set and model are exemplified via the following case. The related data are shown in Table 1.

Table 1 The index value

\begin{tabular}{|c|c|c|c|c|c|c|c|c|c|}
\hline & \multirow[t]{2}{*}{ Cost } & \multicolumn{2}{|c|}{ Reliability } & \multicolumn{2}{|c|}{ Robustness } & \multicolumn{2}{|c|}{ Scalability } & \multicolumn{2}{|c|}{ Security } \\
\hline & & $\begin{array}{l}\text { Mean time } \\
\text { between } \\
\text { failures }\end{array}$ & Effectiveness & $\begin{array}{c}\text { Satisfaction } \\
\text { degree }\end{array}$ & $\begin{array}{c}\text { Change } \\
\text { impact rate }\end{array}$ & $\begin{array}{c}\text { Modular } \\
\text { layer degree }\end{array}$ & $\begin{array}{c}\text { The interaction } \\
\text { degree between } \\
\text { modules }\end{array}$ & $\begin{array}{c}\text { The security } \\
\text { of systems }\end{array}$ & $\begin{array}{c}\text { The security } \\
\text { of data }\end{array}$ \\
\hline Weight & 0.05 & 0.1 & 0.17 & 0.25 & 0.07 & 0.08 & 0.06 & 0.11 & 0.11 \\
\hline GEIS1 & 4 & 3 & 4 & 4 & 5 & 2 & 2 & 5 & 4 \\
\hline GEIS2 & 4 & 2 & 2 & 3 & 7 & 3 & 4 & 5 & 5 \\
\hline GEIS3 & 3 & 5 & 3 & 4 & 6 & 2 & 6 & 4 & 6 \\
\hline
\end{tabular}

According to the above process, the sample matrix is 


$$
\begin{aligned}
S M^{1}= & {\left[\begin{array}{ccccccccc}
5 & 3 & 4 & 5 & 5 & 2 & 2 & 5 & 4 \\
4 & 2 & 2 & 3 & 7 & 3 & 4 & 5 & 5 \\
3 & 5 & 1 & 4 & 6 & 2 & 6 & 5 & 6
\end{array}\right] } \\
w & =\left(w_{1}, w_{2}, w_{3}, w_{4}, w_{5}, w_{6}, w_{7}, w_{8}, w_{9}\right) \\
& =\left(\begin{array}{lllllllll}
0.05,0.1,0.17,0.25,0.07,0.08,0.06,0.1,0.1
\end{array}\right) \\
\Rightarrow S M^{2}= & {\left[\begin{array}{lllllllll}
0.20 & 0.30 & 0.68 & 1.00 & 0.35 & 0.16 & 0.12 & 0.50 & 0.4 \\
0.20 & 0.20 & 0.34 & 0.75 & 0.49 & 0.24 & 0.24 & 0.50 & 0.5 \\
0.15 & 0.50 & 0.51 & 1.00 & 0.42 & 0.16 & 0.36 & 0.44 & 0.6
\end{array}\right] }
\end{aligned}
$$

Then the final value is the larger the better, the ideal matrix of this three GEIS is

$\Rightarrow S M^{0}=\left[\begin{array}{lllllllll}0.15 & 0.50 & 0.68 & 1.00 & 0.35 & 0.24 & 0.12 & 0.5 & 0.6 \\ 0.15 & 0.50 & 0.68 & 1.00 & 0.35 & 0.24 & 0.12 & 0.5 & 0.6 \\ 0.15 & 0.50 & 0.68 & 1.00 & 0.35 & 0.24 & 0.12 & 0.5 & 0.6\end{array}\right]$

Then the distance between each GEIS and the ideal matrix $d_{i}(i=1,2,3)$ is calculated via matlab, and the results are shown as follows:

$$
d_{1}=0.2982 \quad d_{2}=0.5609 \quad d_{3}=0.3184
$$

As $d_{1}<d_{3}<d_{2}$, so the first GEIS is the best, and the second GEIS is the worst. Besides, from the data in the table, the satisfaction degree in GEIS1 is higher, which is the same as GEIS3. the values of indices including cost and the mean time between failures in GEIS3 are better then that of GEIS1, but the final optimal result is GEIS1, not GEIS3. The reason is that the adaptability evaluation is a multi-objective problem, and the target is overall optimization not local optimization.

\section{CONCLUSIONS}

According to GQM, this paper proposes a set of adaptability index system, which includes five aspects: Cost, Reliability, Robustness, Scalability and Security. Then the evaluation model is proposed to evaluate GEIS adaptability and exemplified though a case. The research in this paper can rich the adaptability theory and lay a foundation for the optimization of GEIS adaptability.

\section{ACKNOWLEDGMENT}

This work is supported by Technical Secondary Project of Henan Grant JYB2013356.

\section{REFERENCES}

[1] Qu Xiaoting, Ren Jie, "Study on graduate affairs information services of American university ," E -Business and E -Government (ICEE), 2011 International Conference on , Shanghai, China, 2011, pp.1-3.

[2] Bi Xiaolong, "Discussion on the internet information construction for graduate employment," Assets \& Finances in Administration \& Institution, 2011, pp.170-171.

[3] Guo Gang, "Discussion on the information construction for college graduate employment at present," Guide to Business, 2011, pp. 248249.

[4] Wu Caihong, Zhao Jiewen, "The analysis of information construction for college graduate," Journal of Jiaozuo University, 2012, pp. 127-129.

[5] Ying, Li,Yuming, Lin, "On the construction of college graduates employment promotion system and the realization of its function," Business Management and Electronic Information (BMEI), 2011 International Conference on, 2011, pp. 471-474.

[6] Yu Jun, Wang Yang, Li Zhenhua, "Study on College Information Service Platform Based on the Demand-Driven Information Resource," Internet Technology and Applications (iTAP), 2011 International Conference on, 2011, pp. 1-4.

[7] Wu Jie, "The design and implementation of graduate employment information management system for higher vocational college based on Web," University of Electronic Science \& Technology of China, 2011.

[8] Han Xu, "Study on the implementation of the employment information management system," Liaoning Normal University, 2011. 